\title{
PAULO FREIRE E OS ESTUDOS CULTURAIS
}

\author{
POR LUIZ MENNA-BARRETO \\ JEFFERSON AGOSTINI MELLO ${ }^{2}$
}

O Dossiê Paulo Freire, publicado nesta edição da Revista de Estudos Culturais, do Programa de Pós-Graduação em Estudos Culturais da Escola de Artes, Ciências e Humanidades, reúne seis artigos com propostas de diálogo entre áreas distintas do conhecimento e a obra do pedagogo Paulo Freire, ressaltando-se a sua abrangência, interdisciplinaridade e diálogo com o campo da cultura.

Nosso objetivo com esta edição é sinalizar, sem sombra de dúvida, tanto a amplitude como a atualidade do pensamento freireano, nos debates atuais e, mais especificamente, nas áreas de atuação do conjunto de autores.

Assim, no texto inicial, de autoria da professora Lisete Arelaro (FEUSP) e Camila Gomes Arelaro Caetano (PUCSP), são debatidos aspectos políticos e as motivações subjacentes das críticas que vêm sendo difundidas por diversos membros do atual governo brasileiro, notadamente, por aqueles que desde 2019 fazem parte do primeiro escalão do ministério da Educação, entre eles o próprio ministro. O segundo texto, de Aristóteles Berino (UFRRJ), é um convite para explorar as aspectos estéticos, especialmente do ponto de vista dos processos de emancipação, na obra e atuação de Freire. Angélica de Luca (Mestranda FEUSP) e Maria Elena Infante-Malachias (EACH/USP) propõem uma leitura atualizada da prática pedagógica freireana no caso concreto de curso preparatório para o vestibular. No texto seguinte, Ana Cristina Champoudry Nascimento da Silva (FEUSP) nos convida a pensar no porquê de o pensamento de Paulo Freire se constituir em um "clássico" da pedagogia. Luiz Menna-Barreto e Cláudia Espírito-Santo (EACH/USP) exploram possíveis e desejáveis

\footnotetext{
1 Mestre e doutor em Ciências (Fisiologia Humana) pela Universidade de São Paulo em 1981, com Pós-Doutorado na Université de Franche-Comté, França em 1987. Livre-Docente pela Universidade de São Paulo em novembro de 2008 e Titular em 2009. Foi professor do departamento de Fisiologia e Biofísica do Instituto de Ciências Biomédicas da USP entre 1980 e 2005 e, desde 2005 é docente da Escola de Artes, Ciências e Humanidades da USP.

${ }^{2}$ Graduado em Letras pela Universidade Federal de Santa Catarina (1996), mestre em Literatura pela Universidade Federal de Santa Catarina (1999), doutor em Letras (Teoria Literária e Literatura Comparada) pela Universidade de São Paulo (2004) e Livre-Docente na área de Artes, Cultura e Lazer - especialidade Estudos Culturais e Literatura Brasileira. E professor associado da Escola de Artes, Ciências e Humanidades (EACH) da Universidade de São Paulo.
} 


\section{EDITRRIAL}

conexões das propostas de Paulo Freire no entendimento mais profundo dos fatores em jogo na construção dos tempos escolares. Finalmente, fechamos o dossiê com uma reflexão de Bibiana Graeff e Ricardo Gioia (EACH/USP) sobre a incorporação do pensamento freireano em um programa de educação permanente para idosos .

Por meio desse conjunto de textos, o leitor perceberá que as críticas públicas a Freire, advindas de ideólogos do atual governo federal, não são apenas infundadas, como, também, representam um estado de indigência intelectual que Paulo Freire, dada a sua grandeza e ambição transformadora, jamais poderia prever. 